\title{
FUNGSI LEGENDA “ASAL-USUL TELAGA NGEBEL” BAGI MASYARAKAT DESA NGEBEL, KABUPATEN PONOROGO, JAWA TIMUR
}

(The Function of the Legend "The origin of Ngebel Lake" for Society of Ngebel

Village, Ponorogo Rigency, East Java)

\author{
Hening Larasati, Eggy Fajar Andalas \\ Pendidikan Bahasa Indonesia, Universitas Muhammadiyah Malang, \\ J1. Raya Tlogomas No.246, Malang (0341) 551149, \\ Pos-el: heniiiing@gmail.com, eggy@umm.ac.id
}

Diterima 5 Februari 2021

Direvisi 17 Maret 2021

Disetujui 22 April 2021

\section{https://doi.org/10.26499/und.v17i1.3411}

\begin{abstract}
Abstrak : Dalam kehidupan masyarakat Desa Ngebel hidup legenda mengenai asal-usul Telaga Ngebel. Legenda ini hingga saat ini masih hidup di dalam masyarakat dan menjadi bagian penting kehidupan masyarakat desa. Penelitian ini bertujuan mendeskripsikan fungsi legenda asal-usul Telaga Ngebel bagi kehidupan masyarakat Desa Ngebel. Jenis penelitian ini adalah kualitatif dengan pendekatan etnografi. Sumber data penelitian adalah informan dan dokumen. Teknik pengumpulan data dilakukan dengan wawancara dan perekaman. Analisis data menggunakan model Milles dan Huberman. Hasil penelitian menunjukkan legenda ini berfungsi sebagai 1) sistem proyeksi masyarakat, 2) alat pendidikan, 3) hiburan, dan 4) alat pemaksa dan pengawas masyarakat. Berbagai fungsi ini lahir sebagai dampak dari keberadaan legenda asal-usul Telaga Ngebel yang hidup dalam masyarakat antargenerasi. Berbagai nilainilai ini diwariskan antargenerasi sehingga dipersepsi sebagai kebenaran bersama dan menjadi nilai kultural yang mengikat dalam kehidupan masyarakat Desa Ngebel.
\end{abstract}

Kata kunci : fungsi, legenda, Telaga Ngebel

Abstract: There is a legend about the origin of Ngebel Lake in the life of the people of Ngebel Village. This legend is still alive in the community and become an important part of the life of the village community. The goal of this study is to explain the role of the legend of the origin of Ngebel Lake in the life of the people of Ngebel Village. This form of study is qualitative with ethnographic approach. Sources of research data are informants and documents. Data collection techniques were carried out by interview and recording. Data analysis using Milles and Huberman's model. The results show that this legend functions as 1) a community projection system, 2) an educational tool, 3) entertainment, and 4) a means of coercion and community monitoring. These numerous roles have arisen as a result of the existence of a legend of the origin of the Ngebel Lake, which lives in an intergenerational society. These various values are passed down between generations so that they are perceived as shared truths and become binding cultural values in the life of the people of Ngebel Village.

Keywords: function, legend, Lake Ngebel

\section{PENDAHULUAN}

Sastra lisan merupakan ilmu yang menelaah kebudayaan tradisional yang ada pada masyarakat serta diturunkan oleh nenek moyang dan kemudian diteruskan kepada generasi-generasi selanjutnya. Sejalan dengan pendapat Danandjaja (1997, hlm. 1) yang menyatakan bahwa sastra lisan merupakan kebudayaan milik semua 
orang, yang meluas serta diteruskan dari waktu ke waktu secara lisan, sebagai suatu pengingat.

Salah satu bentuk sastra lisan, yaitu legenda. Legenda merupakan cerita lisan yang berkisah mengenai seorang tokoh ataupun tempat yang dalam pengisahannya masih dapat dikenali keberadaannya di dunia ini (Andalas, 2018a, hlm. 10-11; Danandjaja, 1997, hlm. 73; Pratiwi, Andalas, \& Dermawan, 2018). Dengan kata lain, tokoh ataupun tempat-tempat yang ada di dalam cerita tidak sepenuhnya asing karena menggunakan tempat ataupun tokoh yang dikenali keberadaannya di dunia ini. Karenanya, legenda memiliki kedudukan sebagai hal yang profan dalam kehidupan masyarakat (Sulistyorini \& Andalas, 2017). Bentuk ini berbeda dengan mite yang dianggap sebagai hal yang sakral bagi masyarakat pemiliknya (Andalas, 2015, hlm. 2, 2017, hlm. 22; Aristama, Andalas, \& Sugiarti 2020, hlm. 1; Hutomo, 1991, hlm. 63).

Dalam kehidupan masyarakat Desa Ngebel, Kabupaten Ponorogo, Jawa Timur, hidup legenda Telaga Ngebel. Telaga Ngebel memiliki pesona alam yang indah. Keadaan alam yang masih natural menjadi daya pikat bagi wisatawan. Telaga ini juga sangat sejuk sebab berlokasi di kaki Gunung Wilis yang mempunyai ketinggian 734 meter di atas permukaan laut. Telaga Ngebel dikelilingi oleh rimbunan pepohonan yang menambah kesejukan dan keasrian kawasan ini. Telaga ini memiliki luas sekitar $5 \mathrm{~km}$. Air yang ada di telaga bersumber dari Kanal Selatan.

Di balik keindahan alam yang dimiliki Telaga Ngebel, dalam kehidupan masyarakat sekitar tumbuh legenda yang dipercaya sebagai kebenaran mengenai asal-usul adanya
Telaga Ngebel. Masyarakat mempercayai legenda mengenai sosok ular naga bernama Baru Klinting yang hidup di telaga ini. Masyarakat Desa Ngebel mempercayai bahwa Baru Klinting merupakan sosok penyebab adanya Telaga Ngebel.

Legenda Baru Klinting berkisah tentang sosok ular naga yang berubah wujud menjadi manusia berupa anak kecil yang kelaparan dan meminta-minta makanan. Namun, tak ada satu pun warga yang memperdulikanya, sehingga membuat Baru Klinting geram kemudian Baru Klinting menantang warga untuk mencabut lidi yang ia tancapkan di tanah. Akan tetapi, tidak seorang pun yang dapat mencabut lidi tersebut. Saat itu juga, Baru Klinting mencabut batang lidi yang tertancap di tanah dengan begitu mudahnya. Saat itu juga, keanehan terjadi. Dari lidi itu mengucur air deras, terus-menerus hingga seluruh kampung terendam oleh air tersebut dan terciptalah Telaga Ngebel.

Hingga saat ini, legenda mengenai asal-usul terciptanya Telaga Ngebel masih hidup dalam masyarakat Ponorogo, khususnya Desa Ngebel. Masyarakat mempercayai jika legenda ini merupakan sebuah kebenaran. Karenanya, masyarakat sekitar sangat menjaga perilaku dan sopan santun ketika berada di Telaga Ngebel. Masyarakat percaya bahwa bentuk perilaku yang tidak baik akan menyebabkan naga Baru Klinting akan murka.

Berdasarkan penelusuran, ditemukan beberapa penelitian yang berkaitan dengan penelitian ini. Pertama, peneliti yang melihat keberadaan Telaga Ngebel dalam perspektif pariwisata (Mustikawati, Sunarti, \& Pangestuti, 2017, hlm. 2; Saputro \& Albrianingrum, 
2019; Supriadi, Wahjuni, \& Widiyahseno, 2020; Syafrudin, 2009). Peneliti-peneliti tersebut melihat potensi dan strategi pengembangan wisata terhadap Telaga Ngebel. Kedua, peneliti yang melihat keberadaan Telaga Ngebel dalam perspektif historis dan budaya (Harinayuetik, 2021; Karlina, 2007; Mitanto \& Nurcahyo, 2012, hlm. 48; Putri \& Nugraha, 2017, hlm. 206). Penelitipeneliti tersebut melihat nilai budaya dan perkembangan kebudayaan yang dimiliki masyarakat Ngebel. Ketiga, peneliti yang melihat keberadaan tradisi larungan yang ada di Telaga Ngebel dalam perspektif hukum Islam (Pramuditya, 2018, hlm. 53).

Berdasarkan hal tersebut, penelitian terhadap fungsi legenda Telaga Ngebel bagi masyarakat Desa Ngebel belum pernah dilakukan. Padahal, pemahaman terhadap fungsi ini sangat penting. Hal ini karena keberadaan sebuah cerita lisan dalam suatu masyarakat tidak bisa hanya dianggap sebagai cerita penglipur lara semata (Andalas, 2014, hlm. 9, 2015, hlm. 2, 2017, hlm. 21), tetapi juga berkaitan dengan dimensi budaya, sosial, ekonomi, hingga spiritual masyarakat pemiliknya (Pratiwi, Andalas, \& Dermawan, 2018; Sulistyorini \& Andalas, 2017, hlm. 152157).

Penelitian ini bertujuan mendeskripsikan fungsi legenda Telaga Ngebel bagi kehidupan masyarakat Desa Ngebel, Ponorogo, Jawa Timur. Penelitian ini penting dilakukan dengan beberapa alasan berikut. Pertama, sebagai produk budaya masyarakat, keberadaan legenda Telaga Ngebel menjadi bagian dalam kehidupan masyarakat. Cerita ini sedikit banyak mempengaruhi norma dan nilai-nilai yang hidup di masyarakat. Karenanya, dengan memahami hal tersebut akan diperoleh pengetahuan mengenai cara berpikir masyarakatnya (Dundes, 1969, hlm. 471). Kedua, penelitian terhadap fungsi legenda Telaga Ngebel bagi kehidupan masyarakat Desa Ngebel belum pernah dilakukan oleh peneliti lainnya.

\section{KERANGKA TEORI}

\subsection{Pengertian Legenda}

Karya sastra dapat dibedakan menjadi dua bagian, yaitu (1) sastra tidak lisan, dan (2) sastra lisan. Sastra tidak lisan merupakan karya sastra yang diciptakan oleh pengarangnya dalam bentuk teks atau tulisan, sementara sastra lisan merupakan cerita yang sifatnya kelisanan serta diteruskan secara lisan dari generasi tua ke generasi muda atau selanjutnya.

Hutomo (1991, hlm. 1) menyatakan sastra lisan merupakan kesusastraan yang mencakup berbagai ungkapan kesusastraan warga dalam suatu kebudayaan yang telah tersebar luas dan diteruskan secara berpindah-pindah dari mulut ke mulut. Sastra lisan tergolong ke dalam cerita lisan, yang merupakan peninggalan budaya nasional serta memiliki nilai-nilai yang layak disempurnakan atau dikembangkan serta dimanfaatkan untuk kehidupan saat ini dan di kehidupan yang akan datang, dalam kaitannya dengan pemeliharaan pada apresiasi sastra.

Sastra lisan di Indonesia pada setiap daerah memiliki perbedaan dari daerah satu dengan daerah yang lainnya. Wujud sastra lisan pun juga beragam antara lain, (1) bahasa rakyat, (2) nyanyian rakyat, (3) cerita prosa rakyat, dan lain sebagainya. Cerita prosa rakyat adalah cerita yang sudah ada sejak dahulu kala yang hidup dan berkembang di 
lingkungan masyarakat dan diturunkan secara lisan dan bersifat tradisional.

Legenda merupakan bagian dari prosa rakyat yang hampir menyerupai ciri-ciri mitos, yakni dianggap telah benar-benar terjadi, namun dianggap tidak suci. Dalam legenda manusia berperan sebagai tokoh, meski terkadang diceritakan memiliki sifat-sifat yang luar biasa (berbau mistis) karena dibantu oleh makhluk ghaib atau astral (Danandjaja, 1994, hlm. 50)

\subsection{Teori Fungsi}

Fungsi merupakan suatu tugas yang memiliki manfaat tertentu. Demikian juga dengan karya sastra, memiliki fungsi dalam masyarakat. Menurut Malinowski (Endraswara, 2009, hlm. 125) fungsi dari komponen-komponen kebudayaan digunakan sebagai pemenuh kebutuhan-kebutuhan intuisi manusia serta kebudayaan itu sendiri.

Teori yang digunakan dalam penelitian ini adalah teori fungsi yang dikemukakan oleh William R. Bascom. Sebagaimana yang diungkapkan oleh Bascom (Danandjaja, 1997, hlm. 19) legenda ialah bagian dari sastra lisan yang mempunyai fungsi terhadap masyarakat pemiliknya, yaitu :

1) Sebagai sistem proyeksi (system projection).

Sastra lisan dapat dikatakan sebagai alat proyeksi atau angan-angan suatu kolektif. Berfungsi sebagai sistem proyeksi karena mencerminkan kehidupan masyarakat pemiliknya yang mempunyai harapan atau angan-angan.

2) Sebagai alat pendidikan anak.

Setiap sastra lisan memiliki nilai-nilai edukatif yang dapat dijadikan sebagai alat pendidikan anak. Pesan yang terdapat dalam cerita mampu memberikan dampak positif bagi anak. Anak akan belajar melalui cerita yang disampaikan, sehingga menjadikannya pribadi yang lebih baik.

3) Sebagai hiburan.

Sastra lisan merupakan cerita penglipur lara bagi masyarakat pemiliknya dan diturunkan antargenerasi.

4) Sebagai alat pemaksa dan pengawas. Sastra lisan berfungsi sebagai alat pemaksa dan pengawas karena dalam kehidupannya, masyarakat memiliki norma-norma yang berlaku dan wajib dipatuhi oleh setiap anggota kolektifnya. Norma-norma tersebut bertujuan untuk mengatur dan menjaga kehidupan bermasyarakat serta agar masyarakat mampu hidup selaras dan sejahtera.

\section{METODE PENELITIAN}

Jenis penelitian ini adalah kualitatif. Pendekatan yang digunakan adalah etnografi. Peneliti turun ke lapangan untuk memperoleh data secara langsung. Sumber data penelitian ini adalah informan dan dokumen. Informan penelitian, yaitu Bapak A (60 tahun) merupakan sesepuh Desa Ngebel dan Bapak H (32) merupakan Jogoboyo Desa Ngebel. Pemilihan kedua informan didasarkan pada pengetahuannya terhadap legenda Telaga Ngebel dan kedudukannya dalam struktur sosial masyarakat sangat penting. Berbagai hal yang berkaitan dengan pergelaran adatistiadat melibatkan kedua tokoh tersebut. Di sisi lain, dokumen yang dimaksud adalah literatur yang berasal dari jurnal dan buku yang berkaitan dengan tujuan penelitian digunakan untuk mendukung pemahaman terhadap permasalahan penelitian. 
Untuk mengumpulkan data digunakan teknik wawancara dan perekaman. Wawancara dilakukan kepada kedua informan dengan wawancara tidak terstruktur. Artinya, peneliti mempersiapkan daftar pertanyaan sebagai acuan dan tidak menggunakannya secara berurutan (Pratiwi, Andalas, Dermawan, \& Maryaeni, 2018, hlm. 73; Sugiarti, Andalas, \& Setiawan, 2020, hlm. 77). Bergantung pada situasi ketika wawancara berlangsung. Aktivitas wawancara kemudian direkam. Hasil rekaman ditranskripsi dan ditransliterasi ke dalam bahasa Indonesia. Berbagai data tersebut kemudian dianalisis menggunakan teknik analisis data Miles \& Huberman (1992, hlm. 16), yaitu reduksi, penyajian data, interpretasi, dan penarikan kesimpulan.

\section{HASIL DAN PEMBAHASAN}

Berikut dipaparkan mengenai hasil analisis terhadap fungsi legenda Telaga Ngebel bagi kehidupan masyarakat Desa Ngebel. Sebelum pembahasan mengenai hal tersebut, terlebih dahulu disajikan mengenai legenda Asal-Usul Telaga Ngebel yang hidup di masyarakat Desa Ngebel. Penyajian mengenai legenda ini penting sebagai konteks untuk memahami fungsi legenda Telaga Ngebel bagi kehidupan masyarakat Desa Ngebel.

\subsection{Legenda Asal-Usul Telaga Ngebel}

Dalam kehidupan masyarakat Desa Ngebel dipercaya bahwa munculnya Telaga Ngebel merupakan hasil dari peristiwa magis yang terjadi di masa lalu. Berdasarkan wawancara dengan informan diperoleh legenda Telaga Ngebel yang hidup di masyarakat Desa Ngebel sebagai berikut.
Masyarakat mempercayai bahwa pada masa lalu terdapat sepasang suami istri yang sudah lama menikah tetapi belum diberi keturunan. Keduanya memohon kepada Dewa agar segera diberi keturunan. Permohonannya lantas dikabulkan. Betapa kagetnya mereka karena anak yang dilahirkan bukanlah seorang manusia, tetapi seekor ular naga. Ular naga ini diberi nama Baru Klinting.

Di tengah kesedihan karena harus menghadapi kenyataan bahwa anak mereka adalah seekor ular naga, kedua pasangan suami istri ini tidak henti-henti meminta kepada Dewa agar anak mereka dapat berubah menjadi manusia. Keduanya bertapa di sebuah gua hingga akhirnya mendapat petunjuk jika ingin anaknya berubah menjadi manusia, Baru Klinting harus bertapa dan melingkarkan tubuhnya di sekeliling gunung Wilis selama 300 tahun.

Setelah hampir 300 tahun, tubuh Baru Klinting ternyata belum mampu menyentuh ekornya. Ia tidak kehilangan akal. Ia menjulurkan lidahnya agar dapat melingkari gunung Wilis dengan sempurna. Akan tetapi, usahanya sia-sia karena lidahnya dipotong oleh orang tuanya menjadi sebuah tombak. Meski begitu, Baru Klinting tetap melanjutkan tapa bratanya hingga suatu saat masyarakat desa menyelenggarakan hajatan pernikahan anak kepala desa. Warga desa bergotong royong mencari kayu bakar di hutan. Ketika seorang warga memotong kayu, betapa terkejutnya mereka ternyata kayu tersebut mengeluarkan darah. Batang pohon pun dipenuhi dengan daging. Tanpa berpikir panjang warga sekitar mengambil daging tersebut dan membagi-bagikannya kepada warga desa. 
Setelah daging ular naga Baru Klinting habis dimakan warga, barulah Baru Klinting berubah menjadi seorang manusia berwujud anak kecil. Baru Klinting kecewa karena dagingnya dimakan oleh warga desa. Baru Klinting kemudian mendatangi hajatan kepala desa untuk meminta makan. Akan tetapi, ia malah diusir dan tidak ada yang memperdulikannya. Hingga seorang wanita tua bernama Nyi Latung tidak tega melihatnya. Ia menolong Baru Klinting dan memberinya makan. Baru Klinting lantas memberi petunjuk kepada Nyi Latung agar menaiki lesung.

Keesokan harinya, Baru Klinting datang kembali ke tempat hajatan dan membuat sayembara. Ia berseru barang siapa mampu mencabut batang lidi yang ia tancapkan ke tanah, ia akan meninggalkan desa. Ternyata tidak ada satupun warga desa yang mampu mencabutnya. Seketika itu juga Baru Klinting mencabut lidi tersebut dan mulai mengucur air yang sangat deras dari lubang bekas tancapan lidi. Lambat laun karena derasnya aliran air terendamlah desa tersebut menjadi Telaga Ngebel. Satu-satunya orang yang selamat adalah Nyi Latung. Warga desa yang tenggelam di Telaga Ngebel berubah menjadi ikan Ngongok.

Legenda tersebut merupakan legenda yang hidup di masyarakat Desa Ngebel. Masyarakat mempercayai bahwa Telaga Ngebel hingga saat ini masih ditunggu oleh seekor ular naga. Akibat dari perbuatan nenek moyang mereka yang tidak ramah terhadap jelmaan ular naga, bencana terjadi kepada seluruh warga desa. Legenda ini terus diwariskan oleh masyarakat kepada generasi-generasi muda. Selain itu, keberadaan legenda ini juga mempengaruhi kehidupan masyarakat Desa Ngebel.

\subsection{Fungsi Legenda Asal-Usul Telaga Ngebel bagi Masyarakat Desa Ngebel}

Sebagai bagian dari sastra lisan, legenda tidak sekadar memberikan hiburan belaka, akan tetapi juga mampu memberi pencerahan pada jiwa. Dapat dikatakan bahwa legenda mampu memberi manfaat bagi masyarakat, sastra lisan akan menghasilkan fungsifungsi dan kedudukan tertentu. Fungsifungsi tersebut berhubungan dengan keperluan serta kepentingan anggota masyarakat pemiliknya. Berikut penjelasannya.

\subsubsection{Sistem Proyeksi}

Sastra lisan memiliki beberapa fungsi tertentu bagi kehidupan masyarakat pemiliknya, yaitu sebagai sistem proyeksi atau alat cerminan angan-angan suatu kolektif (Danandjaja, 1997, hlm. 19). Terkait dengan fungsi sastra lisan tersebut, legenda asal-usul Telaga Ngebel menciptakan suatu tujuan atau angan-angan yang diharapkan oleh masyarakat Desa Ngebel. Hal ini tercermin dari pandangan dunia masyarakat Desa Ngebel dalam melihat keselarasan yang harus dijaga masyarakat desa. Keselarasan ini berkaitan dengan hajat hidup masyarakat desa dengan keberadaan ular naga yang hidup di Telaga Ngebel. Masyarakat Desa Ngebel setiap tahunnya melaksanakan risalah do'a dan ritual larung sesaji. Aktivitas ini dilakukan sebagai bentuk permohonan kepada penunggu Telaga Ngebel agar senantiasa melindungi desa mereka dan menjauhkan segala malapetaka yang akan terjadi di desa. 
Keberadaan Telaga Ngebel tampak telah menjadi bagian dalam sistem spritual masyarakat dan mewujud dalam perilaku laku ritual (Andalas, 2014, hlm. 30; Endraswara, 2009, hlm. 125). Dalam kehidupan masyarakat Desa Ngebel, para sesepuh desa membuat kesepakatan mengenai penyelenggaraan risalah do'a dan ritual larung sesaji sebagai wujud penghormatan, pengharapan, sekaligus rasa syukur atas berbagai berkah yang diberikan oleh Telaga Ngebel terhadap masyarakat desa. Hal ini ditegaskan oleh salah seorang narasumber, yaitu Pak A (wawancara pada hari minggu, 10 Januari 2021, pukul 15.00 WIB) yang menyatakan sebagai berikut.

"Telogo Ngebel, Telogo sing paling keramat. Tiap tahun ada orang kecelakaan. Ada pendapat sesepuh dikei ritualan, tolak bala"

("Telaga Ngebel, Telaga yang paling keramat. Setiap tahun ada orang kecelakaan. Ada pendapat sesepuh agar diberi ritual, tolak bala")

Risalah do'a dan ritual larung sesaji dilaksanakan pada setiap 1 Suro di Telaga Ngebel. Telaga Ngebel dijadikan sebagai tempat dilaksanakannya ritual larung sesaji karena Telaga Ngebel dianggap sebagai telaga yang keramat serta erat kaitannya dengan mitos Baru Klinting dan Nyi Latung. Menurut wawancara dengan Pak $\mathrm{H}$ (pada hari sabtu, 23 Januari 2021, pukul 18.26 WIB), sebagian besar masyarakat Desa Ngebel mempercayai bahwa ular naga Baru Klinting merupakan salah satu sosok penunggu Telaga Ngebel.

Risalah do'a dan ritual larung sesaji yang dilakukan oleh masyarakat Desa Ngebel merupakan sarana memohon keselamatan dan tolak bala, selain itu risalah do'a dan ritual larung sesaji dilaksanakan sebagai wujud syukur terhadap Tuhan atas berkah yang telah diberikan. Masyarakat Desa Ngebel meyakini dan akan selalu melaksanakan risalah do'a dan ritual larung sesaji dengan harapan mendapat keselamatan dan terhindar dari peristiwa buruk. Hal ini memperlihatkan yang dikemukakan oleh Bascom (Danandjaja, 1997, hlm. 19), yaitu sastra lisan, dalam konteks ini legenda, berfungsi sebagai sistem proyeksi, yakni menjadi alat cerminan angan-angan suatu kolektif.

Angan-angan atau harapan yang dirasakan oleh suatu masyarakat merupakan sebuah hal yang lumrah, karena dengan angan-angan atau harapan tersebut masyarakat memiliki harapan akan perubahan yang lebih baik akan terjadi di masa yang akan datang.

\subsubsection{Alat Pendidikan Anak}

Keberadaan legenda asal-usul Telaga Ngebel tidak hanya berfungsi sebagai hiburan semata. Legenda asal-usul Telaga Ngebel dalam kehidupan masyarakat juga memiliki fungsi sebagai alat pendidikan bagi anak. Alat pendidikan tidak selalu mengacu pada pendidikan formal, tetapi pendidikan kultural yang didasarkan pada basis nilai-nilai yang hidup di dalam masyarakat (Andalas, 2018b).

Melalui cerita legenda asal-usul Telaga Ngebel, anak-anak mampu mengembangkan pikirannya guna mengambil nilai-nilai positif yang terkandung dalam cerita sekaligus membuang jauh-jauh nilai negatif dari pikirannya. Menurut Pak H (wawancara pada hari sabtu, 23 Januari 2021, pukul 18.26 WIB) legenda asal-usul Telaga Ngebel biasanya diceritakan kepada anak-anak, hal tersebut sudah menjadi 
kebiasaan yang telah dilakukan sejak dulu. Berikut kutipannya.

"Ya, diceritakan. Diceritakan pada saat acara kumpul keluarga, sudah turun-temurun"

Legenda asal-usul Telaga Ngebel mengandung unsur fungsi sebagai alat pendidikan anak, dalam hal pendidikan moral. Pendidikan moral yang terdapat dalam legenda asal-usul Telaga Ngebel dapat menumbuhkan sifat budi pekerti anak-anak agar selalu berbuat baik, tolong menolong, serta saling berbagi.

Tolong menolong maksudnya sebagai manusia sudah seharusnya saling membantu. Karena dikisahkan bahwa Baru Klinting kelaparan dan meminta makan kepada warga desa, akan tetapi Baru Klinting diusir dan tidak ada seorang pun yang memperdulikannya, hingga Baru Klinting bertemu dengan Nyi Latung yang baik hati dan mau menolongnya dengan membawa Baru Klinting ke rumahnya dan memberi Baru Klinting makanan.

Anak-anak juga dapat belajar agar tidak menjadi pelit seperti warga yang terdapat dalam legenda asal-usul Telaga Ngebel. Terlihat bahwa warga desa sangat pelit karena tidak mau memberi makan Baru Klinting, padahal daging yang diambil adalah daging milik Baru Klinting.

Selanjutnya, anak-anak juga dapat mencontoh kebaikan Nyi Latung dan memahami bahwa perbuatan yang baik maka akan memberi balasan yang baik pula. Hal tersebut dapat dilihat ketika Nyi Latung berbuat baik dengan menolong Baru Klinting, ia mendapat balasan yang baik pula. Nyi Latung adalah satu-satunya manusia yang selamat dari bencana yang melanda desa.

\subsubsection{Sebagai Hiburan}

Selain menjadi alat pendidikan anak, sastra lisan juga berfungsi sebagai hiburan. Sejalan dengan pendapat Bascom (Danandjaja, 1997) yang menyatakan bahwa suatu sastra lisan mempunyai beberapa fungsi tertentu bagi masyarakat yang memilikinya yaitu sebagai hiburan (hlm. 19).

Suatu cerita pasti menyandang fungsi menghibur. Menghibur tidak hanya menggambarkan kegembiraan saja, namun juga memberi informasi serta pengetahuan dapat dikatakan sebagai hiburan (Warto, 2012, hlm. 57). Pentikainen (1997) memperlihatkan bahwa dalam sebuah pertunjukan sastra lisan selalu terdapat dimensi hiburan yang berfungsi untuk memberikan efek hibur kepada partisipan yang terlibat dalam peristiwa tersebut. Pertunjukan yang dimaksud adalah peristiwa penceritaan yang dilakukan oleh pendongeng (pencerita) kepada orangorang yang mendengarkan (Finnegan, 1979, hlm. 28). Dalam menuturkan legenda Telaga Ngebel kepada anggota masyarakat Desa Ngebel, legenda ini juga menjadi sarana hiburan. Masyarakat menikmati, bahkan meyakini, peristiwa penceritaan dan kisah-kisah ajaib yang ada dalam legenda ini.

Dalam kehidupan masyarakat Desa Ngebel, cerita ini biasanya masih diceritakan oleh ibu-ibu desa kepada anak-anaknya pada waktu tertentu, seperti sebelum tidur. Selain itu, masyarakat sekitar juga suka menceritakan kisah legenda ini kepada para wisatawan ataupun orang yang berasal dari luar desa yang berkunjung ke Telaga Ngebel. Pak H (wawancara 
pada hari sabtu, 23 Januari 2021, pukul 18.26 WIB) memperkuat hal ini dengan mengatakan bahwa legenda ini biasanya diceritakan ketika sedang kumpul keluarga. Mendengarkan cerita tidak hanya menumbuhkan rasa hormat kepada Telaga Ngebel tetapi juga menjadi sarana mempererat ikatan di dalam keluarga.

Selain itu, dengan perkembangan teknologi digital saat ini, banyak reproduksi legenda Telaga Ngebel dalam bentuk-bentuk digital. Hal ini seperti usaha penganimasian Legenda Telaga Ngebel yang dilakukan oleh Triyana (2011). Selain itu juga terdapat penceritaan ulang yang dilakukan melalui kanal video youtube. Berbagai hal tersebut memperlihatkan fungsi legenda ini sebagai hiburan masyarakat.

\subsubsection{Sebagai Alat Pemaksa dan Pengawas}

Bascom (Danandjaja, 1997, hlm. 19) berpendapat bahwa sastra lisan memiliki berbagai macam fungsi khusus bagi masyarakat yang memilikinya, yaitu sebagai alat pemaksa serta pengawas agar norma-norma dalam masyarakat tidak dilanggar oleh anggota kolektifnya. Hal tersebut penting untuk dimengerti atau dipahami sebagai fungsi yang akan tetap menjadi patokan setiap kolektifitasnya dalam berkehidupan.

Diketahui bahwa Telaga Ngebel merupakan tempat yang keramat dan dikaitkan dengan sosok dalam legenda asal-usul Telaga Ngebel, yaitu Baru Klinting dan Nyi Latung, sehingga jika berada di tempat tersebut diharuskan menjaga perilaku, sesuai dengan yang disampaikan oleh Pak $\mathrm{H}$ (wawancara pada hari sabtu, 23 Januari 2021, pukul 18.26 WIB).
Apabila ada orang yang melanggar norma yang telah berlaku, maka orang tersebut akan mengalami malapetaka. Pak A (wawancara pada hari minggu, 10 Januari 2021, pukul 15.00 WIB), mengatakan bahwa sering ada orang tenggelam di Telaga Ngebel. Masyarakat Desa Ngebel mempercayai bahwa hal itu terjadi karena orang tersebut telah melanggar norma-norma yang berlaku di Desa Ngebel.

Peristiwa-peristiwa buruk yang terjadi di Desa Ngebel menghadirkan aturan-aturan tidak tertulis, akan tetapi disepakati bersama agar dipatuhi. Dalam kehidupannya, masyarakat Desa Ngebel serta warga lain sangat menjaga perilaku apabila berada di Telaga Ngebel, menjaga perilaku untuk tidak mengucapkan kata-kata kotor, meludah, merusak alam atau perilaku yang sekiranya membuat penunggu Telaga Ngebel marah. Hal itu dilakukan untuk menjaga keselarasan hidup serta menghindari timbulnya hal-hal yang tidak diinginkan dalam kehidupan mereka.

Tata nilai ini tidak hanya bersifat magis. Dalam perspektif ekologis, berbagai aturan ini memperlihatkan pandangan masyarakat Desa Ngebel dalam menjalin keselarasan hidup masyarakat desa dengan alam sekitarnya (Abdullah, 2017, hlm. 15; Sugiarti, Andalas, Saraswati, \& Kusniarti, 2019, hlm. 12). Legenda menjadi medium bagi masyarakat desa dalam menjaga laku kehidupan terhadap sesama manusia, dan manusia dengan alam yang telah menghidupi masyarakat Desa Ngebel. 


\section{PENUTUP}

\section{Simpulan}

Penelitian ini bertujuan mendeskripsikan fungsi legenda Asal-Usul Telaga Ngebel bagi kehidupan masyarakat Desa Ngebel. Berdasarkan analisis ditemukan bahwa legenda ini berfungsi sebagai 1) sistem proyeksi masyarakat, 2) alat pendidikan, 3) hiburan, dan 4) alat pemaksa dan pengawas masyarakat. Berbagai fungsi ini lahir sebagai dampak dari keberadaan legenda asal-usul Telaga Ngebel yang hidup dalam masyarakat antargenerasi. Berbagai nilai-nilai ini diwariskan antargenerasi sehingga dipersepsi sebagai kebenaran bersama dan menjadi nilai kultural yang mengikat dalam kehidupan masyarakat Desa Ngebel.

Penelitian ini hanya menyoroti fungsi legenda bagi kehidupan masyarakat. Penelitian lanjutan terkait keterkaitan legenda asal-usul Telaga Ngebel dengan dimensi spiritualitas masyarakat dapat dilakukan.

\section{DAFTAR PUSTAKA}

Abdullah, O. S. (2017). Ekologi Manusia dan Pembangunan Berkelanjuan. Gramedia Pustaka Utama.

Andalas, E. F. (2014). Mitos Mbah Bajing dalam Sastra Lisan Masyarakat Dusun Kecopokan Kecamatan Sumberpucung Kabupaten Malang. Universitas Negeri Malang.

Andalas, E. F. (2015). Mitos-Mitos Kabupaten Malang: Cara Orang Jawa dalam Menjelaskan Dunianya.
Puitika, 11(2), 150-162.

Andalas, E. F. (2017). Dampak dan Fungsi Sosial Mitos Mbah Bajing bagi Kehidupan Spiritual Masyarakat Dusun Kecopokan Kabupaten Malang Jawa Timur. Puitika, 13(1), 20-31.

Andalas, E. F. (2018a). Cerita Rakyat dan Tradisi Masyarakat Agraris Nusantara: Mitos Dewi Sri (Jawa) dan Legenda Putri Mandalika (Sasak). In P. Karyanto (Ed.), KisahKisah Perempuan dan Cerita Rakyat Nusantara (pp. 1-12). Kajian Sastra dan Budaya Universitas Airlangga.

Andalas, E. F. (2018b). Meninjau Kembali Identitas Jawa: Panji Sebuah Representasi Identitas Lokal Jawa Timur. Retrieved from researchgate.net

Aristama, M. F., Andalas, E. F., \& Sugiarti, S. (2020). Dampak dan Fungsi Mite Semar bagi Kehidupan Masyarakat Lereng Gunung Arjuna. Poetika, 8(1), 1-12. https://doi.org/10.22146 /poetika.55300

Danandjaja, J. (1994). Folklor Indonesia: Ilmu Gosip, Dongeng dan lain-lain. Pustaka Utama Grafiti.

Dundes, A. (1969). Folklore as a Mirror of Culture. Elementary English, 46(4), 471-482. Retrieved from http://www.jstor.org/stable/41386 525

Endraswara, S. (2009). Metodologi Penelitian Folklor. Yogyakarta: Media Presindo.

Finnegan, R. H. (1979). Oral Poetry: Its Nature, Significance, and Social Context. Cambridge University Press.

Harinayuetik, A. W. (2021). Tradisi Larungan di Telaga Ngebel Perpsektif Islam. Inovatif, 7(1), 1-15. 
Retrieved

from http://jurnal.staih.ac.id/index.php /inovatif/article/view/189

Hutomo, S. S. (1991). Mutiara yang Terlupakan. HISKI.

Karlina, S. (2007). Proses Belajar Kebudayaan pada Masyarakat Desa Ngebel Kecamatan Ngebel Kabupaten Ponorogo. Universitas Negeri Malang.

Miles, B. M., \& Huberman, M. (1992). Analisis Data Kualitatif Buku Sumber Tentang Metode-metode Baru. UIP.

Mitanto, M., \& Nurcahyo, A. (2012). Ritual Larung Sesaji Telaga Ngebel Ponorogo (Studi Historis dan Budaya). Jurnal Sejarah Dan Pembelajarannya, 2(2), 36-53. https://doi.org/10.25273/ajsp.v2i2. 1459

Mustikawati, T. A., Sunarti, S., \& Pangestuti, E. (2017). Analisis Pengembangan Sarana Prasarana Obyek Wisata Alam Telaga Ngebel dalam Meningkatkan Kesejahteraan Ekonomi Masyarakat. Jurnal Administrasi Bisnis, 53(2), 1-10. Retrieved from http://administrasibisnis.studentjo urnal.ub.ac.id/index.php/jab/articl e/download/2202/2598

Pentikainen, J. (1997). Ritual. In T. A. Green (Ed.), Folklore: An Encyclopedia of Beliefs, Customs, Tales, Music, and Art (pp. 733-736). ABC-CLIO.

Pramuditya, F. E. (2018). Tradisi Larungan Sesaji Ditinjau dari Hukum Islam. Universitas Islam Indonesia.

Pratiwi, Y., Andalas, E. F., \& Dermawan, T. (2018). Penelitian Sastra Kontekstual. Kota Tua.

Pratiwi, Y., Andalas, E. F., Dermawan, T., \& Maryaeni, M. (2018). Metode Penelitian Sastra Lisan Kontekstual. Kota Tua.
Putri, N. S., \& Nugraha, O. A. (2017). Perbandingan Struktur, Fungsi, dan Nilai Budaya pada Legenda Telaga Ngebel. Pena Literasi, 3(2), 201-222. https://doi.org/10.26740/jpi.v3n2. p201-222

Saputro, A. W., \& Albrianingrum, S. (2019). Wisata Telaga Ngebel Kabupaten Ponorogo Tahun 1993 2000. Avatara, 7(1), 1-13. Retrieved from

https://jurnalmahasiswa.unesa.ac.i d/index.php/avatara/article/view /27960/25582

Sugiarti, Andalas, E. F., \& Setiawan, A. (2020). Desain Penelitian Kualitatif Sastra. UMM Press.

Sugiarti, S., Andalas, E. F., Saraswati, E., \& Kusniarti, T. (2019). Ekologi Budaya: Studi Ekologi dalam Bingkai Kajian Sastra Interdisipliner. Umm Press.

Sulistyorini, D., \& Andalas, E. F. (2017). Sastra Lisan: Kajian Teori dan Penerapannya dalam Penelitian. Malang: Madani.

Supriadi, D., Wahjuni, E., \& Widiyahseno, B. (2020). Pengembangan Destinasi Desa Wisata Alam Hutan melalui Program PIID PEL di Desa Ngebel Kecamatan Ngebel Kabupaten Ponorogo. Jurnal Administrasi Pemerintahan Desa, 1(2), 75-81. Retrieved from http://villages.pubmedia.id/index. php/villages/article/view/6

Syafrudin, D. (2009). Larung Risalah Do'a di Telaga Ngebel sebagai Daya Tarik Wisata Budaya Kabupaten Ponorogo. Universitas Sebelas Maret.

Triyana, Y. (2011). Perancangan Film Animasi Dua Dimensi (2D) Tentang Legenda Terjadinya Telaga Ngebel di Kabupaten Ponorogo. Universitas 
Undas Vol 17, Nomor 1, Juni 2021: 63--74

Negeri Malang.

Warto. (2012). Wayang Beber Pacitan:

Fungsi, Makna, dan Usaha

Revitalisasi. Paramita, 22(1), 56-68.

https://doi.org/10.15294/paramita.

v22i1.2914 